\title{
Testing for Helicobacter pylori in primary care: trouble in store?
}

\author{
R Foy, J M Parry, L Murray, C B J Woodman
}

\begin{abstract}
Study objective-To assess the role of testing for Helicobacter pylori in the management of dyspeptic patients in primary care.

Design-Selective review of literature frequently quoted to support use of $\boldsymbol{H}$ pylori testing.

Main results-Testing for $H$ pylori and referral of only positive cases for endoscopy aims to reduce the number of "unnecessary" endoscopies. Patients with negative results may receive short-term reassurance and subsequently place fewer demands on health services. However, studies to date have only assessed this practice in secondary care settings. Given the relatively high prevalence of both dyspepsia and $H$ pylori infection, the transfer of this practice to primary care may lead to a paradoxical increase in endoscopy referrals. Identification of $H$ pylori and prescribing of eradication treatment also aims to reduce endoscopy referrals. No primary care trials have yet assessed this approach. Given that fewer than one in four of dyspeptic patients have peptic ulceration, a high proportion may fail to respond to eradication treatment and subsequently require referral for endoscopy. The longer term clinical and psychosocial sequelae of treating or labelling patients with an infection associated with gastric cancer remain unknown.

Conclusions-Given uncertainty concerning the possible adverse effects of $\mathrm{H}$ pylori testing in primary care, we suggest a moratorium on its use in this setting until results from relevant clinical trials become available.

(F Epidemiol Community Health 1998;52:305-309)
\end{abstract}

Centre For Cancer

Epidemiology,

University of

Manchester, Christie

Hospital NHS Trust,

Kinnaird Road,

Withington,

Manchester M20 4QL

R Foy

J Parry

C B J Woodman

Department of Public Health and

Epidemiology, Queens

University, Belfast

L Murray

Correspondence to:

Dr Foy.

Accepted for publication 28 August 1997

The management of dyspepsia places a major clinical and economic burden on the health service. $^{12}$ General practitioners are under increasing pressure to contain increases in endoscopy referrals and prescribing of acid suppressing drugs.

Most people who experience dyspepsia do not seek medical attention as the majority of episodes are self limiting and treated by over the counter medication. Nevertheless, approximately one quarter of people with dyspeptic symptoms consult their general practitioner, ${ }^{3}$ accounting for up to $4 \%$ of all consultations. ${ }^{4}$

Dyspepsia may signify the onset of major upper gastrointestinal disease but clinical identification of the underlying cause is problematic as symptoms poorly predict underlying pathology. ${ }^{5-8}$ Investigation, usually with upper gastrointestinal endoscopy, is required to establish a definitive diagnosis. This creates a problem: only endoscopy can ensure a definite diagnosis but referral of all dyspeptic patients would increase pressures on already stretched endoscopy services.

The discovery of Helicobacter pylori in $1983,{ }^{9}{ }^{10}$ and growing knowledge about its associations with upper gastrointestinal pathology are driving major changes in the management of dyspepsia. ${ }^{11} H$ pylori eradication therapy cures and prevents recurrence of peptic ulcer disease but the utility of eradication in the management of dyspepsia from other causes remains unproved. ${ }^{12-14}$

Despite this, and other gaps in the evidence base, recent consensus guidelines recommend that $H$ pylori testing becomes an integral component in the management of dyspeptic patients in primary care. ${ }^{15}{ }^{16} \mathrm{~A}$ number of local guidelines also support this position (telephone survey of North West medical advisers, 1995).

We present a commentary on evidence frequently quoted to support the adoption of two commonly promoted practices (see fig 1) that use $H$ pylori testing in primary care: (1) $H$ pylori testing with endoscopy for those who test positive and reassurance or symptomatic treatment for negative cases; (2) H pylori testing and eradication therapy in positive cases with endoscopy reserved for symptomatic nonresponders, and reassurance or symptomatic treatment for negative cases.

Both strategies set an age related threshold for referral for endocopy, usually 45 years, to minimise the likelihood of failing to detect gastric malignancy, which is uncommon below this age. ${ }^{17} 18$

\section{Means of detecting $H$ pylori in primary care}

$H$ pylori infection can be diagnosed by invasive

(histology, culture, and testing for Campylobacter-like organisms) require biopsy specimens to be taken at endoscopy and their use in primary care is therefore less appropriate.

Two non-invasive methods generally advocated for use in primary care are urea breath testing and serology. Breath tests detect labelled carbon dioxide hydrolysed from 13Cor 14C-labelled urea by the $H$ pylori urease enzyme. Although highly sensitive and specific, this method has two main drawbacks, patients usually have to fast before examination; and the capital equipment costs are high. ${ }^{19}$

Serological testing for IgG and IgA antibodies to $H$ pylori is highly sensitive and specific ${ }^{20-23}$ 


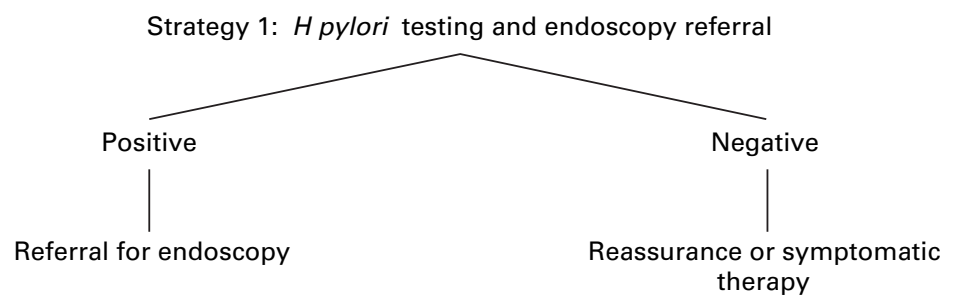

Strategy 2: $H$ pylori testing and eradication therapy

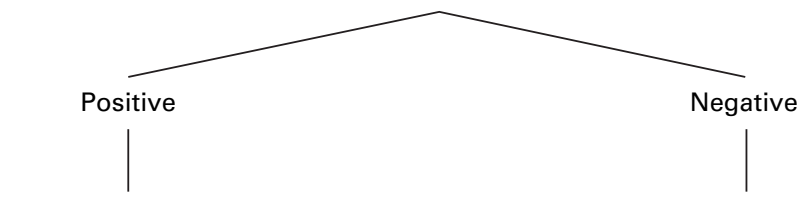

Eradication therapy

Reassurance or symptomatic therapy

Endoscopy referral if no response to treatment

Figure 1 Strategies proposed for the treatment of young patients with dyspepsia in primary care. associated with reduced general practitioner consultation and prescribing rates. ${ }^{39-41} \mathrm{~A}$ negative $H$ pylori test may also confer some reassurance and result in similar benefits within the year after testing. ${ }^{37}$ However, dyspepsia is a chronic, fluctuating syndrome with intermittent periods of breakthrough symptoms, ${ }^{42}$ and extended follow up is required to demonstrate the sustainability of such benefits. Presumed savings made by identifying and thus not investigating seronegative patients may diminish in the longer term should reassurance from a negative $H$ pylori test prove insufficient, or dyspeptic symptoms unrelated to $H$ pylori infection (for example, gastro-oesophageal reflux disease) recur.

All studies published to date tested for $H$ pylori in patients already referred for endoscopy. It is not possible to ascertain the proportions of new and prevalent cases, although it may be reasonable to assume that the latter group predominates and that results from these studies cannot be generalised to new dyspeptic patients presenting in primary care.

Given the high background levels of $H$ pylori seropositivity in the population, ${ }^{43}$ a substantial proportion of dyspeptic patients with no evidence of peptic ulceration will test positive. Guidelines to general practitioners could make it explicit that $H$ pylori testing should only take place after the decision to refer for endoscopy. ${ }^{15}$ However, experience suggests that availability of investigations, especially near patient tests, in primary care leads to an expansion of their original indications. ${ }^{44}{ }^{45}$ Thus, if seropositivity is accepted as a criterion for investigation, and the threshold for use of $H$ pylori testing is lowered, a paradoxical increase in endoscopy referrals may occur. Over-reliance on $H$ pylori testing as a criterion for referral may also distract general practitioners from considering other risk factors in the pathogenesis of peptic ulceration, for example, smoking and alcohol intake.

\section{Identification of $\boldsymbol{H}$ pylori and eradication therapy before endoscopy}

The rationale behind this approach is that eradication therapy should cure and therefore avoid the need for endoscopy referral in most patients with peptic ulcer disease. ${ }^{46-48}$ Costs of maintenance acid suppressing drugs would be reduced for patients with peptic ulcer disease and, possibly, a proportion of patients with non-ulcer dyspepsia who respond to either true therapeutic or placebo effects.

Decision analyses suggests testing and eradication may be of equal or greater cost effectiveness compared with conventional management. ${ }^{4749}{ }^{50}$ However, conclusions are particularly sensitive to costs used, for example, of endoscopy or acid suppressing agents, with $H$ pylori detection and investigation becoming more cost effective as endoscopy charges and drug costs increase.

On current evidence, less than one in four $H$ pylori positive dyspeptic patients have peptic ulcer disease and can be expected to benefit from eradication therapy. ${ }^{30}{ }^{34}$ This proportion may be less in dyspeptic patients presenting for 
the first time in primary care. ${ }^{52}$ Treating all seropositive patients would therefore result in the majority of cases, most of whom would have non-ulcer dyspepsia, receiving an unproved treatment. Symptoms may recur or persist in many of these patients and up to one quarter of those with peptic ulcers not initially responding to eradication therapy (because of antibiotic resistance or poor compliance). General practitioners, unable to discriminate on clinical grounds between unresponsive peptic ulceration and non-ulcer dyspepsia, would have to decide whether to refer for endoscopy or start longer term treatment with acid suppressing drugs. Urea breath testing could determine whether eradication had occurred but sufficient clinical uncertainty might persist in the minds of both general practitioners and patients to prompt an endoscopy referral. If urea breath testing indicated the presence of active $H$ pylori infection, consideration would have to be given to non-compliance or antibiotic resistance, and investigation of antibiotic resistance would necessitate endoscopy.

Therefore, the cost effectiveness of this approach in primary care could be undermined if a large number of symptomatic nonresponders are referred for endoscopy or require further courses of acid suppressing drugs. Further disadvantages of this practice lie in its potential to induce antibiotic resistence through the widespread use of eradication therapy. The prevalence of $H$ pylori resistance to metronidazole, commonly incorporated in eradication regimens, is around $40 \%$ in the UK. ${ }^{53}$ However, metronidazole resistance does not necessarily prevent eradication and use of metronidazole for other indications will probably, at present, play a more significant part in inducing resistance. Side effects of current eradication regimens are frequent but perceived as severe enough by less than $10 \%$ of patients to warrant withdrawing from treatment. $^{54-56}$ However, insufficient counselling of patients before beginning eradication treatment may also undermine effectiveness.

\section{Trouble in store? Psychosocial sequelae} of $H$ pylori testing

$H$ pylori has been defined as a category one (definite) carcinogen by the WHO/IARC. ${ }^{57}$ An association with gastric cancer has been determined with a relative risk of between 2 and $9{ }^{58-62}$ although the absolute risk to people with evidence of infection is probably small. A precise aetiological role of $H$ pylori in the development of gastric cancer has not yet clearly been established. ${ }^{63}$ Conflicting evidence of an association with ischaemic heart disease also exists. ${ }^{64}{ }^{65}$ Until the long term results of intervention studies are known, the identification and eradication of $H$ pylori remains unproved in the prevention of gastric cancer, or even ischaemic heart disease. ${ }^{13}$

Such knowledge places clinicians and patients in a difficult and uncertain position and there is pressure to prescribe eradication therapy if $H$ pylori has been identified. ${ }^{66}$ Infection with $H$ pylori has not been shown to influence consulting rates in dyspeptic patients ${ }^{67}$ but
KEY POINTS

- General practitioners are under increasing pressure to contain the prescribing and referral costs of treating dyspepsia.

- The availability of non-invasive tests for the detection of $H$ pylori is driving major changes in the treatment of dyspepsia by general practitioners.

- Practices based upon $H$ pylori detection in primary care may paradoxically increase prescribing costs and endoscopy referrals.

- Patient labelling from knowledge of $H$ pylori status can also change consulting behaviour.

- A moratorium on testing in primary care may be necessary until results from relevant trials are available.

knowledge of $H$ pylori status may modify both patient and doctor behaviour in unforeseen ways. The process of screening or disease labelling after a positive result may have psychosocial costs, ${ }^{68} 69$ including subsequent changes in health seeking behaviour. ${ }^{70}$

Doctors and patients may perceive the relative risk of gastric cancer in $H$ pylori infected people as being sufficiently high to warrant action. Individual perceptions of risk, ${ }^{72}$ coupled with the widespread uptake of serological testing, could have important effects on both patient and doctor behaviour, for example, by increasing consultation rates and lowering thresholds for further investigation. Severity or frequency of dyspeptic symptoms correlate poorly with decisions to consult: health beliefs and knowledge play more significant parts, especially if symptoms are perceived to be associated with cancer or ischaemic heart disease.$^{73}$ Alternatively, providing patients with a negative result, or eradicating $H$ pylori in those with positive results, may yield improved psychosocial outcomes. No trial has yet assessed the psychological consequences of $H$ pylori serological testing and treatment.

Information given to patients before and after testing is also likely to influence subsequent consulting behaviour. At present, few general practitioners report discussing the likelihood of gastric cancer with patients after a positive $H$ pylori test. ${ }^{74}$ Patient labelling could be avoided by prescribing eradication treatment to dyspeptic patients empirically without ascertaining $H$ pylori status but the cost effectiveness and acceptability of this approach remain uncertain.

\section{Conclusion}

Testing for $H$ pylori is being incorporated into routine clinical practice in primary care..$^{75} 76$ Furthermore, media coverage of $H$ pylori and promotion of screening by commercial health agencies may fuel public pressure for routine testing. Yet widespread serological testing in primary care could have substantial long term psychosocial and resource implications. 
Use of $H$ pylori testing and eradication therapy could yet be proved to deliver significant advantages over conventional management of dyspepsia in primary care. ${ }^{14}$ Understandably, general practitioners are keen to adopt methods perceived as more cost effective in treating a common and costly symptom. ${ }^{77}$ However, evidence from secondary care based studies is being inappropriately applied to primary care settings despite important differences in the prevalence of disease in these populations. ${ }^{11}$ Interpretation of these studies is further limited by nonrandomised or retrospective designs and comparatively short follow up periods that may fail to detect longer term adverse effects related to patient labelling.

There is a need for scepticism in the face of premature claims of cost effectiveness to prevent unnecessary medicalisation of patients' lives as well as to guide further research. Similar experiences have occurred in the past when, for example, it was argued that use of cholesterol lowering drugs in the primary prevention of ischaemic heart disease threatened "to turn a large percentage of the healthy population into patients, at a substantial potential cost to the NHS". ${ }^{78}$ Given the uncertainty concerning the benefits and risks of $H$ pylori testing in primary care, we suggest a moratorium on its use in this setting until results from relevant clinical trials are available.

Funding and declaration of interest: JP, RF, and CBJW are running a trial in which Cortecs Diagnostics Ltd are providing 750 Helisal ( $H$ pylori) testing kits free of charge; $\mathrm{LM}$ is involved in a trial jointly funded by the South \& West R\&D Directorate and Glaxo Welcome. Both studies are being run independently of the companies, neither of which have control over the dissemination of results.

1 Song F, Maynard A. Functional dyspepsia: a review of scientific Health Economics, University of York, 1994.

2 Ryder SD, O'Reilly S, Miller RJ, et al. Long term acid suppressing treatment in general practice. BMF 1994;308:827pressing.

3 Jones R, Lydeard S. Prevalence of symptoms of dyspepsia in the community. BMF 1989;298:30-2.

4 McCormick A, Fleming D, Charlton J. Morbidity statisitics from general Practice. Fourth National Study 1991-92. London: Office of Population Censuses and Surveys, 1995.

5 Holdstock G, Harman M, Machin D, et al. Prospective testing of a scoring system designed to improve case selection for upper gastrointestinal investigation. Gastroenterology 1986;90:1164-9.

6 Davenport PM, Morgan AG, Darnborough A. Can preliminary screening of dyspeptic patients allow more effective use of investigational techniques? BMF 1985;290:217-19.

7 Talley NJ, Weaver AL, Tesmer DL, et al. Lack of discriminant value of dyspepsia subgroups in patients referred for upper endoscopy. Gastroenterology 1993;105: 1378-86.

8 Mansi C, Savarino V, Sandro Mela G, et al. Are clinical patterns of dyspepsia a valid guideline for appropriate use of terns of dyspepsia a valid guideline for appropriate use of
endoscopy? A report on 2253 dyspeptic patients. A $m \neq$ Gastroenterol 1993;88:1011-15.

9 Marshall BJ. Unidentified curved bacillus on gastric epithelium in active chronic gastritis. Lancet 1983;i:1273-5.

10 Warren JR. Unidentified curved bacillus on gastric epithelium in active chronic gastritis. Lancet 1983;i:1273.

11 Delaney BC. Role of Helicobacter pylori in gastrointestina disease: implications for primary care of a revolution in management of dyspepsia. Br f Gen Pract 1995;45:489-94.

12 Sander JO, Veldhuyzen van Zanten, Sherman PM. Indications for treatment of Helicobacter pylori infection: a
systematic overview. Can Med Assoc $\mathcal{F}$ 1994;150:189-98.

13 NIH Consensus Development Panel. Helicobacter pylori in peptic ulcer disease. $7 A M A$ 1994;272:65-9.

14 Moore RA. Helicobacter pylori and peptic ulcer. A systematic review of effectiveness and an overview of the economic benefit of implementing what is known to be effective. Oxford: Health of implementing what is known to be effective. Oxford: Health Unit, 1995 .
15 British Society of Gastroenterology. Dyspepsia management guidelines. London: BSG Guidelines in Gastroenterology, 1996.

16 European Helicobacter pylori Study Group. Current European concepts in the management of Helicobacter pylori infection. The Maastricht Consensus Report. Gut 1997;41: $8-13$.

17 Williams B, Luckas M, Ellingham JHM, et al. Do young patients with dyspepsia need investigation? Lancet 1988;ii: $1349-51$.

18 Gear MWL, Barnes RJ. Endoscopic studies of dyspepsia in a general practice. BMF 1980;280:1136-7.

19 Marshall BJ. Helicobacter pylori. Am f Gastroenterol 1994;89:116-28.

20 Crabtree JE, Shallcross TM, Heatley RV, et al. Evaluation of a commercial ELISA for serodiagnosis of Helicobacter pylori infection. $\mathcal{F}$ Clin Pathol 1991;11:326-8.

21 Lin SK, Lambert JR, Schembri M, et al. A comparison of diagnostic tests to determine Helicobacter pylori infection. 7 Gastroenterol Hepatol 1992;7:203-9.

22 Talley NJ, Kost L, Haddad A, et al. Comparison of commercial serological tests for detection of Helicobacter pylori antibodies. F Clin Microbiol 1992;30:3146-50.

23 Provonost AD, Rose SL, Pawlak JW, et al. Evaluation of a new immunodiagnostic assay for Helicobacter pylori antibody detection: correlation with histopathological and microbiological results. f Clin Microbiol 1994;32:46-50.

24 Moayyedi P, Carter AM, Catto A, et al. Validation of a rapid whole blood test for diagnosing Helicobacter pylori infection. BMf 1997;314:119.

25 Borody TJ, Andrews P, Shortis NP. Evaluation of whole blood antibody kit to detect active Helicobacter pylori infection. Am f Gastroenterol 1996;91:2509-12.

26 Duggan A, Logan R, Knifton A, et al. Accuracy of near-patient blood tests for Helicobacter pylori. [Letter]. Lancet 1996;348:617.

27 Moayyedi P, Axon ATR. Validation of a rapid whole blood test for diagnosing Helicobacter pylori infection. [Letter]. BMF 1997;314:1690-1.

28 Stone MA, Mayberry JF, Wicks ACB, et al. The Helisal test - an assessment of readability and diagnostic accuracy. Gut 1996;39 (suppl 2):A110.

29 Cutler A, Schubert A, Schubert T. Role of Helicobacter pylori serology in evaluating treatment success. Dig Dis Sci 1993;38:2262-6.

30 Sobala GM, Crabtree JE, Pentith JA, et al. Screening dyspepsia by serology to Helicobacter pylori. Lancet 1991; 338:94-6.

31 Morgan AG, Crabtree JE, Heatley RV, et al. Role of Helicobacter pylori serology in the initial assessment of patients with dyspepsia. [Abstract]. Gut 1991;32:T98.

32 Mendall MA, Goggin PM, Marrero JM, et al. Role of Helicobacter pylori serology in screening prior to endoscopy. Eur $\mathcal{F}$ Gastroenterol Hepatol 1992;4:713-17.

33 Collins JAS, Bamford KB, Sloan JM, et al. Screening for Helicobacter pylori antibody could reduce endoscopic workload in young dyspeptic patients. Eur $\mathcal{F}$ Gastroenterol Hepatol 1992;4:991-3.

34 Patel P, Mendall MA, Khulusi S, et al. Salivary antibodies to Helicobacter pylori: screening dyspeptic patients before endoscopy. Lancet 1994;344:511-12.

35 Tham TC, McLaughlin N, Hughes DF, et al. Possible role of Helicobacter pylori serology in reducing endoscopy workload. Postgrad Med f 1994;70:809-12.

36 Mendall MA, Jazrawi RP, Marrero JM, et al. Serology for Helicobacter pylori compared with symptom questionnaires in screening before direct access endoscopy. Gut 1995;36:330-3.

37 Patel P, Khulusi S, Mendall M, et al. Prospective screening of dyspeptic patients by Helicobacter pylori serology. Lancet 1995;346:1315-18.

38 Briggs AH, Sculpher MJ, Logan RPH, et al. Cost effectiveness of screening for and eradication of $H$ pylori in management of dyspeptic patients under 45 years of age. BMF 1996;312:1321-5.

39 Jones R. What happens to patients with non-ulcer dyspepsia fter endoscopy? Practitioner 1988;232:75-8.

40 Hansen JM, Bytzer P, Bondesen S, et al. Efficacy and outcome of an open access endoscopy service. Dan Med Bull 1991;38:288-90.

41 Bytzer P, Moller Hansen J, et al. Empirical H2-blocker therapy or prompt endoscopy in management of dyspepsia. Lancet 1994;343:811-16.

42 Kay L, Jorgensen T. Epidemiology of upper dyspepsia in a random population. Prevalence, incidence, natural history, and risk factors. Scand $\mathcal{F}$ Gastroenterol 1994;29:1-6.

43 Bernersen B, Johnsen R, Bostad L, et al. Is Helicobacter pylori the cause of dyspepsia? BMF 1992;304:1276-9.

44 Hobbs FDR, Broughton PMG, Kenkre JE, et al. Comparison of the use of four desktop analysers in six urban general practices. Br F Gen Prac 1992;42:317-321.

45 Rink E, Hilton S, Szczepura A, et al. Impact of introducing near patient testing for standard investigations in general practice. BMF 1993;307:775-8.

46 Cottrill $M$. Who should get $\mathrm{H}$ pylori eradication therapy? Prescriber 1994;19 Nov:61-2.

47 Phillips C, Moore A. Implementing evidence-based medical interventions: the cost-effectiveness of Helicobacter pylori diagnosis and eradication. British fournal of Medical Economics 1996;10:47-57.

48 Axon ATR. Chronic dyspepsia: who needs endoscopy? Gastroenterology 1997;112:1376-80. 
49 Fendrick M, Chernew ME, Hirth RA, et al. Alternative management strategies for patients with suspected peptic management strategies for patients with suspectec

50 Silverstein MD, Petterson T, Talley NJ. Initial endoscopy or empirical therapy with or without testing for Helicobacter pylori for dyspepsia: a decision analysis. Gastroenterology 1996;110:72-83

51 Vaira D, Miglioli M, Mule P, et al. Prevalence of peptic ulcer in Helicobacter pylori positive blood donors. Gut 1994;35: 309-12.

52 Heikkinen M, Pikkarainen P, Takala J, et al. Etiology of dyspepsia: four hundred unselected consecutive patients in general practice. Scand F Gastroenterol 1995;30:519-23.

53 Walt RP. Metronidazole-resistant $\mathrm{H}$ pylori - of questionable clinical importance. Lancet 1996;348:489-90.

54 Hosking SW, Ling TK, Chung SCS, et al. Duodenal ulcer healing by eradication of Helicobacter pylori without anti-acid treatment: randomised controlled trial. Lancet 1994;343:508-10.

55 de Boer W, Driessen W, Jansz A, et al. Effect of acid suppression on efficacy of treatment for Helicobacter pylori infecsion on efficacy of treatment for
tion. Lancet 1995;345:817-20.

56 Goddard AF, Logan RPH, Lawes S, et al. Metronidazole or tinidazole with omeprazole and clarithromycin for the eradication of H pylori. [Abstract]. Gut 1996;38 (suppl 1):W49

57 IARC Monographs in the evaluation of carcinogenic risks to humans. Schistosomes, liver flukes and Helicobacter pylori. Lyon: International Agency for Research in Cancer, 1994 61.

58 Forman D, Newell DG, Fullerton F, et al. Association between infection with Helicobacter pylori and risk of gastric cancer: evidence from a prospective investigation. $B M \mathcal{Y}$ 1991;302:1302-5.

59 Parsonnet J, Friedman GD, Vandersteen DP, et al. Helicobacter pylori infection and the risk of gastric carcinoma. N Engl f Med 1991;325:1127-31.

60 Nomura A, Stemmermann GN, Chyou P-H, et al. Helicobacter pylori infection and gastric carcinoma among Helicobacter pylori infection and gastric carcinoma among J132-6.

61 Eurogast Study Group. An international association between Helicobacter pylori infection and gastric cancer. Lancet 1993;341:1359-62.

62 Forman D, Webb P, Parsonnet J. H pylori and gastric cancer. Lancet 1994;343:243-4.
63 Webb PM, Forman D. Helicobacter pylori as a risk factor for cancer. Ballieres Clin Gastroenterol 1995;9:563-82

64 Whincup PH, Mendall MA, Perry IJ, et al. Prospective relations between Helicobacter pylori infection, coronary heart disease and stroke in middle aged men. Heart 1995;75: 568-72.

65 Rathbone B, Martin D, Stephens J, et al. Helicobacter pylori seropositivity in subjects with acute myocardial infarction. Heart 1996;76:308-11.

66 Axon A, Forman D. Helicobacter gastroduodenitis: a serious infectious disease. $B M F$ 1997;314:1430

67 Barnes RJ, Uff JS, Dent JC, et al. Long-term follow up of patients with gastritis associated with Helicobacter pylori infection. Br f Gen Pract 1991;41:286-8.

68 Marteau TM. The psychological costs of screening. BMf 1989;299:527.

69 Cockburn J, Staples M, Hurley SF, et al. Psychological consequences of screening mammography. $\mathcal{F}$ Med Screen 1994; 1:7-12.

70 Bull AR, Campbell MJ. Assessment of the psychological impact of a breast screening programme. Br f Radiol 1991; 64:510-15.

71 Haynes RB, Sackett DL, Taylor DW, et al. Changes in absenteeism and psychosocial function due to hypertension screening and therapy among working men. $N$ Engl f Med 1978;299:741-4.

72 Calman KC. Cancer: science and society and the communication of risk. BMF 1996;313:799-802.

73 Lydeard S, Jones R. Factors affecting the decision to consult with dyspepsia: comparison of consulters and nonconsulters. $\mathscr{f} R$ Coll Gen Pract 1989;39:495-8.

74 Parry J, Foy R, Woodman CBJ. What do general practitioners tell patients prior to testing for $\mathrm{H}$ pylori? $\mathrm{Br} \mathcal{F}$ Gen Pract 1997; 47:311-312.

75 Babbs $\mathrm{C}$ (on behalf of the $\mathrm{H}$ pylori Review Group). $\mathrm{H}$ pylori-associated gastroduodenal disease: survey of British Physicians' views. [Abstract]. Gut (suppl 1) 1995;37:A87.

76 Logan RPH, Aldous JC, Ramsay M, et al. Helicobacter pylori, dyspepsia and peptic ulcer: perspectives and practice from dyspepsia and peptic ulcer: perspectives and practice
primary care. [Abstract]. Gut (suppl 1) 1995;37:A88.

77 Rubin G, Stevens R. Laboratory tests for Helicobacter pylori should become more widely available. [Letter]. BMF 1996;313:172-3.

78 Davey Smith G, Pekkanen J. Should there be a moratorium on the use of cholesterol lowering drugs? BMF 1992;304: 431-4. 